\title{
Chlorpromazine consumption of rats under stress
}

\author{
ROBERT L. SOLSO and D. GENE DAVENPORT, St. Louis \\ University, St. Louis, Mo. 63103
}

Animals under electric shock stress selected a diet of dry food mixed with a chlorpromazine solution in greater proportion than a dry food-water diet, while non-stress animals selected the nonchlorpromazine diet, when a moderate $155 \mathrm{mg}$ chlorpromazine/100 cc water) solution was used. Both shocked and non-shocked Ss preferred a weak $(30 \mathrm{mg})$ mixture, and both groups rejected a strong $(80 \mathrm{mg})$ mixture when the alternative was the water solution.

Numerous experiments have supported the theory that deprivation creates needs which increase drive. The underlying theory of many of these studies, which has evolved during the past three decades, is that motivated organisms operationally behave in a manner which tends to reduce the source of motivation. Two general procedures have been employed to support this theory. The first and the more common technique involves depriving animals of a specific nutrient and having a diet rich in that nutrient available to the animal. A second technique involves presenting a strong noxious stimulus and having a diet available which will remove some of the residual effects of that stimulus. These studies have attempted to evaluate the drive properties of dietary components nonessential for life. We call these studies secondary appetitive studies as the animal ingests a diet which reduces the residual effects (such as fear) of strong noxious stimulus.

In some preliminary work, it was found that rats, under demonstrable stress, did not ingest a diet of chlorpromazine solution. It seemed apparent that the explanation for the result was in terms of the probable repulsiveness to rats of the taste of chlorpromazine in solution. The present research was undertaken in order to evaluate an extension of this interpretation. Specifically the present research was designed to further test the relationship between stress and the tendency to choose food mixed with chlorpromazine in a free choice situation.

\section{SUBJECTS}

The Ss were 30 male albino rats of the Sprague-Dawley strain about 100 days old at the beginning of the food adaptation. During both the adaptation and experimental phases, Ss were weighed periodically for possibilities of systematic changes.

\section{PROCEDURE}

Four diets were prepared daily. The first contained $540 \mathrm{~g}$ of Purina Laboratory Chow mixed with $810 \mathrm{cc}$ of tap water and was used as the regular diet for all animals. Three chlorpromazine diets were prepared using a common stock solution of $5.28 \mathrm{~g}$ of chlorpromazine powder dissolved in 4 liters of deionized water. One chlorpromazine diet consisted of $30 \mathrm{mg}$ chlorpromazine per $100 \mathrm{cc}$ water, the second, $55 \mathrm{mg}$ chlorpromazine per $100 \mathrm{cc}$ water and the third, $80 \mathrm{mg}$ chlorpromazine per $100 \mathrm{cc}$ water. Each level was mixed with laboratory chow using a ratio of 3 parts liquid to 2 parts diet.

For five days prior to the main experiment Ss were adapted to a $24 \mathrm{~h}$ deprivation schedule and soft diet involving a 2-choice feeding situation in the home cage. During this period approximately $20 \mathrm{~g}$ of feed/water mixture, mixed with a ratio of $1: 2$ by weight, were presented in 2 cups to each animal for 35 min. Following adaptation, food cups containing approximately $45 \mathrm{~g}$ of feed mixture were presented to each animal, once each day for 22 days. During this period, food with the appropriate chlorpromazine concentration ( $30 \mathrm{mg}, 55 \mathrm{mg}$, or $80 \mathrm{mg}$ ) was presented simultan'orsly with the regular (non-chlorpromazine) diet to three sub-groups of five non-shocked Ss and three subgroups of five shocked Ss. Immediately prior to the presentation of the food cups in the home cage, Ss receiving shock were removed from their home cage, placed in the shock box and given a $2 \mathrm{sec}, 80 \mathrm{~V}$ electrical shock. Both groups were then allowed to feed $35 \mathrm{~min}$ before the cups were removed. The position of the chlorpromazine diet cups and regular cups was randomized daily.

\section{RESULTS AND DISCUSSION}

The results are given below in terms of the three concentrations of chlorpromazine vs non-chlorpromazine diet for (a) stressed animals and (b) non-stressed animals. First, in the $30 \mathrm{mg}$ groups, both stressed and non-stressed animals preferred the chlorpromazine diet on approximately $2 / 3$ of the last 19 days of the experiment. In the $55 \mathrm{mg}$ groups, the non-stressed animals showed a slight but consistent preference for the regular, non-chlorpromazine diet, on 15 days out of 19 test days. However, the performance for the stressed animals was the reverse of that of the non-stressed group, for they preferred the $55 \mathrm{mg}$ diet of chlorpromazine on 15 out of the 19 test days $\left(x^{2}=\right.$ $\mathrm{p}<.001)$. Finally, in the $80 \mathrm{mg}$ groups, both stressed and non-stressed animals preferred the regular, non-chlorpromazine diet on 12 of the 19 test days.

All animals lost weight ranging from $37.8 \mathrm{~g}$ for non-shocked animals on $30 \mathrm{mg} /$ regular diet to $92.6 \mathrm{~g}$ for shocked animals on 80 $\mathrm{mg} / \mathrm{regular}$ diet. As one would expect, the animals who lost the greatest amount of weight consumed the least feed $(r=-.94)$, however the correlation between weight loss and chlorpromazine consumed was positive $(\mathrm{r}=+.77)$.

Probably the most significant aspect of this study is the different preference tendencies of shocked animals compared with non-shocked animals given free choice between a moderately (55 $\mathrm{mg}$ ) tranquilizing diet and regular diet. Apparently even a modest stress produced by the shock situation of the present study is strong enough to create tensions which can be removed by chlorpromazine. The interpretation currently being entertained as being most consistent with the findings emphasizes a conflict between aversive bitter taste and fear reducing characteristics of chlorpromazine. We feel that the consumption of the chlorpromazine has both positive and negative consequences, positive in terms of tranquilizing effects and negative in terms of the aversive taste qualities. The presence of the moderate stress condition increases the positive consequence in the $55 \mathrm{mg}$ group, but does not overcome the increased aversiveness of the stronger $80 \mathrm{mg}$ concentration. At the lower concentrations, when the bitterness was less, both groups preferred the drugged food and at the highest concentrations, both groups tended to prefer the non-drugged diet, although the latter differences failed to reach significance. Researchers (e.g., Engle, 1928; Rogers, 1966) have long demonstrated the adient characteristics of diets with weak concentrations of bitter, sour, and salty chemicals, while in greater concentrations the same $S s$ reject these diets. However, the preference differences between the stressed and non-stressed animals in the moderate drug group cannot be explained in terms of bitterness only. Thus to account for all the data, it could be consistent to presume that for the low concentration groups, the preference for the drugged food resulted in part from the mildly tranquilizing effects as well as any novelty of mild bitterness, which though present at the highest concentration did not counter even in the stress situation the aversiveness of the taste of the chlorpromazine. But in the moderate concentration group, though bitter enough to be rejected by the unstressed animals, the tranquilizing effects when under mild stress resulted in the moderate increase in preference for the chlorpromazine food.

As noted earlier, the preferences were not statistically significant using a high chlorpromazine $(80 \mathrm{mg})$ vs a regular diet, however, there was a tendency to reject the high concentration. Overall food intake was reduced for the $80 \mathrm{mg}$ group, but in spite of this, they consumed a greater amount of chlorpromazine. A high concentration of chlorpromazine may, when ingested, not only dull motor reaction but also sensory discrimination and the capacity for learning new responses. In addition, the high concentration of chlorpromazine may have been sufficiently bitter to minimize any preferential treatment under the rather mild stress conditions studied.

Finally, one of the secondary findings of this study was the indicated high negative relationship between weight loss and chlorpromazine consumed. These data suggest that although the Ss 
consumed less total diet when presinted with the choice between strong concentrations of chlorpromizine and regular diet, they ingested more chlorpromazine than animals given the choice of the weaker concentrations of chlorpromazine and regular diets. The effects of chlorpromazine ingestion were reflected in the changes of body weight.

\section{REFERENCES}

ENGLE, R. Experimentelle untersuchungen uber die Abhangigkeit der Lust und Unlust von der Reizstarke bein Gesclımacksinn. Archiv fur dic gesamte Psychologie. 1928, 64, 1.36. Cited by R. S. Woodworth in Experimental psychology. New York: Holt, 1938.

ROGERS, W., \& ROSEN, P. Novel food preferences in thiamine-deficient rats. Journal of Comparative \& Physiological Psychology. 1966, 61, 1-4.

SOLSO, R. L. The effect of stress on chlorpromazine consumption, United States Public Service Grant, MY-6421 (A), 1963. 